\title{
PLANT PROTECTION - THE SCIENTIFIC CAPABILITY
}

\author{
R.J. FIELD \\ Lincoln University, Canterbury
}

\begin{abstract}
The scientific capability in plant protection in New Zealand has changed, particularly over the last 5-10years. The emphasis on biosecurity and sustainability have brought about discipline alignment to promote areas such as biotechnology, molecular biology and ecology. The overall downturn in primary production, uneven growth across commodity sectors and changing research funding priorities have all impacted on defining the scientific capabilities underpining plant protection. It appears that the human resource in plant plant protection is increasingly drawn from the biological sciences rather than primary production sciences. The emphasis appears to be on a changing scientific capability that is closely aligned to New Zealand's future requirements in addressing biosecurity and sustainability issues.
\end{abstract}

Keywords: scientific capability, research funding, plant protection

\section{INTRODUCTION}

There has been considerable and ongoing debate about a range of issues that impact on the current, national capability in plant protection and the extent to which there has been erosion of this capability over the last decade. The science reforms in New Zealand, leading to the demise of DSIR, MAFTech and other organisations and the establishment of Crown Research Institutes, and the competitive programme funding regime administered by the Foundation for Research Science and Technology (FRST) may represent the significant structural changes as seen by the wider population, but are not the total picture. The contribution of the universities, in terms of research output, the work of postgraduates and the production of graduates is critical to an assessment of overall science capability and potential. A further dimension is the extent to which the overall economic reform in New Zealand plus significant trading trends in primary production commodities have influenced both the nature and extent of plant protection research, technical support and technology transfer. A range of changes that are recognised under the umbrellas of biosecurity and sustainability have influenced both the allocation of research funds from FRST and the priorities established by industry. Thus changes in plant protection and supporting disciplines are as much about qualitative shifts in the key disciplines and industries as they are about perceived erosion of total capability. Some of the relevant issues are understood internationally and are without a simple solution (Lewis 1994).

New Zealand collects more effective statistics on its research performance, funding and changing priorities than at any time in the past. Information from the Ministry of Research Science and Technology (MORST) plus regular reporting from FRST and the annual reports from CRIs and universities have established very useful data sets. Thus funding and research outputs can be attributed to both institutions and to output areas. Unfortunately cross discipline areas such as plant protection are difficult to track, particularly when individual projects are buried within larger programmes. The difficulty in assessing the total cost of plant protection research is recognised by MORST who are initiating an independent survey in 1997. Such a survey would have increased value if it could establish a funding trend pattern and relate this to a measure of the actual requirement for plant protection research based on the needs of the relevant industries, growers and exporters and the understanding of scientists of international trends and the appropriateness of particular lines of investigation. The latter role for scientists enhances

Proc. 50th N.Z. Plant Protection Conf. 1997: 364-368 
rather than diminishes the issue of relevance of research and technology to New Zealand's needs. The level of sophistication required is such that an analysis of this type is unlikely to occur.

In preparing this paper it became apparent that identification of current research requirements in plant protection was difficult and only matched by problems of identifying the current capability and total funding. The lack of both a specific output class for FRST funding, or a major stand alone plant protection institution adds to the difficulty in analysis. It is possible to glean some insight into the position of plant protection by analysing the performance of the key underpinning disciplines of agriculture, horticulture and forestry plus the general biological sciences.

What follow are brief analyses of areas that underpin the plant protection capability. It seems critical to take the future view because unreasonable benchmarking to what was past is significantly confused by shifting priorities in the discipline and changed institutional structures.

\section{THE MOVE AWAY FROM PRIMARY PRODUCTION}

The New Zealand economy has declining reliance on primary production as measured by its contribution to the value of total exports, (Anon. 1990; 1996a). Thus agriculture as a percentage of gross domestic product declined from $7.7 \%$ in 1985 to $5.0 \%$ in 1996 . The qualitative shifts within the sector have seen improved performance from horticulture and dairy products and but an overall decline in traditional areas of meat and wool. The overall performance in the primary sector influences key decisions by industries, communities and individuals. Thus the pattern of investment in research by both public and private sectors, international interest in New Zealand technology and science and the study and career aspirations of young people are all influenced. The issue for plant protection activity and in particular research funding is for it to maintain relativity with other primary production areas, as a minimum, but also for support to reflect any shifts in relative importance.

It can be reasonably argued that many of the basic agronomic factors that underpin primary production have been adequately investigated and that future improvements will be relatively small. This does not apply to plant protection which is constantly changing because of pest control efficacy issues, legislative change driven by environmental and human health issues and the increased openness of the country's borders to pest incursions.

The impact of the white spotted tussock moth (Orgyia thyellina)invasion in Auckland, the scale and efficacy of the eradication programme and the retrospective analysis of the scientific contribution to solving the infestation problem are issues that highlight the need for appropriate resourcing of plant protection (Sinclair et al. 1997). Some plant protection problems are of long standing and can be classified as issues that were waiting to happen. Thus there was no significant prediction that hawkweed (Hieracium spp.) populations in the South Island would develop exponentially over the last twenty years. Efforts at regulating population growth in a cost effective way have not been successful. This maybe an inherent biological problem but more likely it is because of inadequate resourcing of research that could lead to low cost solutions. Similarly there are existing pest problems that have only received scant attention because of their limited national impact, perhaps because of restriction to a small geographical area or impact on a small value commodity. Chilean needle grass (Stipa neesiana) has been present in localised regions of Marlborough and Hawkes Bay for many years, where it has a serious impact on sheep production ( Bourdôt and Hurrell 1987). There is no information on the factors that determine the localisation of the present populations, nor an adequate analysis of the risk of population expansion or methods of control. It is easy to conclude that with the present depression of meat and wool prices that a pest with currently low impact will receive virtually no attention, irrespective of the long term risk.

\section{FUNDING OF RESEARCH}

The public investment in strategic science and technology, (Anon. 1995) forecasts a total increase of $28.2 \%$ from $\$ 257.5 \mathrm{~m}$ in $1995-96$ to $\$ 330 \mathrm{~m}$ in $2000-01$. By 
comparison the projected increase in the primary production sector outputs (Outputs $1,2,3,4$ and 5 ) is $8.5 \%$. The nominal funding level for agriculture will be maintained if funding increases to $\$ 330 \mathrm{~m}$ (Anon. 1996a). The recent statement by the current Minister for Research, Science and Technology (Williamson 1997) reinforces the emphasis that will be placed on technology, with possible further erosion of the base science funding for primary production. The introduction and expansion of the Marsden Fund offers some opportunity but is not intended to support the required applied research. The platform provided by the Public Good Science Fund is augmented by a research component of the Ministry of Education subsidy for postgraduate student research in universities and by industry support. The scale of the latter contributions varies with commodity sector and the financial viability of the industry. The current difficulties faced by the meat and wool industries are not fully offset by greater viability in other sectors. Even if they were, the funding support is not fully transferable, given the species/pest specificity of plant production systems and plant protection.

The net effect of current funding projections for plant production and the associated plant protection is that there is likely to be limited opportunity for expanding the gross scientific capability at a time when international trade policies that relate to pest management are changing in the post-GATT environment. The vulnerability of international trade opportunity to inadequate scientific support for plant protection is a risk that many professionals in the area believe is too great.

\section{DISCIPLINARY SHIFTS IN PLANT PROTECTION}

The twin foci of plant protection in the 1990s are sustainability and biosecurity. The reliance on pesticides, that was the major feature of control strategies of less than a decade ago has been replaced with a research emphasis that seeks to limit or eliminate pesticide use in all areas of primary production. The new focus on biological control technologies requires strong support from agro-ecology, autecological investigations of target species and the application of a wide range of biotechnology, including molecular biology. All of these support disciplines are either largely new or use enhanced approaches to assist in the understanding and development of the new applications to pest control. The ecological studies are concerned with the delicate relationships between two or more species with the aim of suppressing the impact of the target pest species. The emphasis on sustainability has led to a mindset change that is more concerned with learning how to control pest populations within predetermined limits than a drive to eliminate the last individual. The importance of biotechnology and molecular biology is wider than biological control and is involved in biosecurity, particularly the development of crop resistance, to both pests and pesticides, and the production of genetically modified foods.

The weight of the current specific shifts, particularly in biosecurity, are considerable and driven in large part by new legislation.

The current approaches to plant protection have reduced reliance on studies of plant production, pesticide efficacy and perhaps a range of in depth biological studies of key pests. Thus the thorough analysis of the biological features and life cycle characteristics of difficult to control weeds is seemingly no longer a priority, although how the introduction of biological control affects can occur without this basic knowledge is difficult to comprehend.

The net effect of the shifts in the focus of research and investigation are linked to movement in funding priorities and more particularly the skill set and education of those employed to conduct the research. The performance of universities in meeting this changing demand for graduates is analysed in a subsequent section.

\section{HUMAN RESOURCE PLANNING}

There is no evident policy on human resource planning for either the primary production sector or the specific area of plant protection. The lack of detailed priority setting gives tertiary institutions little chance to match graduate output to employment needs.

There is no simple analysis of trends in the human resource attributable to plant protection research in research institutions and universities and to key support activities 
that are typically industry-based and linked to product development and sales. The perception is that there has been considerable downsizing of the number of research professionals in the last ten years, with a corresponding reduction in industry-based personnel. There are no firm statistics on current capability and how it relates to earlier capacity levels. Scrutiny of the membership of the New Zealand Plant Protection Society and its predecessor, the New Zealand Weed and Pest Control Society does reveal some interesting shifts. Peak membership was in 1985 but there has been stability in research institution and university membership over the last ten years (Table 1 ). The major decline is in industry membership, which would not have impacted on more fundamental plant protection studies.

\section{TABLE 1: New Zealand members of the Plant Protection Society/New Zealand Weed and Pest Control Society, by sector.}

\begin{tabular}{cccccc}
\hline Year & $\begin{array}{c}\text { Research } \\
\text { institution }\end{array}$ & University & Industry & $\begin{array}{c}\text { Organisation/ } \\
\text { association }\end{array}$ & $\begin{array}{c}\text { Private } \\
\text { individual }\end{array}$ \\
\hline 1975 & 45 & 5 & 99 & 36 & 57 \\
1980 & 80 & 14 & 110 & 30 & 56 \\
1985 & 133 & 23 & 127 & 38 & 76 \\
1990 & 121 & 26 & 70 & 31 & 56 \\
1995 & 125 & 25 & 58 & 12 & 42 \\
\hline
\end{tabular}

An alternative approach to investigating human resource requirements and interest in plant protection is to determine the changing pattern in the production of graduates in relevant disciplines. The New Zealand Vice Chancellors' Committee produces an annual analysis of Graduate Employment in New Zealand (Anon. 1996b). It is possible to plot trends over the last 23 years. The information for the areas of Agriculture/ Horticulture, Forestry and Biological Sciences are relevant to issues of the supply of graduates to plant protection, although this is not identified as a discreet area. The Royal Society of New Zealand Standing Committee on Primary Production Sciences and Technologies has used the NZVCC data to produce a draft report that demonstrates some alarming negative trends in the production of graduates in primary production, (Cameron 1996). Thus the number of graduates being employed as scientists or technicians in 1995 was 27, falling from a peak of 102 in 1981. This, at a time when the total number of graduates has been increasing rapidly, particularly since about 1990 . Of the 20,374 New Zealand graduates in 1995 (Anon. 1996b), 53\% were in employment of which less than $0.25 \%$ of the total were in primary production science. This compares to a figure of $1 \%$ in 1986. The decline in employment in primary production has been dramatic and is no doubt mirrored by changes in the sub-set of plant protection.

Some caution should be exercised in the analysis of those graduates that progress to primary production science and specifically plant protection. The changing form of the underpinning disciplines, with greater emphasis on the ecological sciences, biotechnology and molecular biology means that the biological sciences are probably providing a greater number of graduates to plant protection than was the case a decade ago. The number of biology graduates continues to increase with a 6\% increase from 1994 to 1995 and a $15.5 \%$ increase to 1996 . Of the 976 graduates in the biological sciences in 1996 only 36 majored in botany and 50 in plant sciences, with a further 166 in biology. The animal sciences were better represented with 229 graduates in zoology and 104 in genetics and physiology.

The requirement for postgraduate qualifications for employment as a scientist in plant protection suggests that a biological science first degree background is more likely than from agriculture, horticulture or forestry. The percentage of graduates proceeding to further study in 1996 ranged from 3.3\% in Forestry to $20.1 \%$ in Agriculture/ Horticulture and $49.3 \%$ in Biological Sciences. Typically the figure for Agriculture/ Horticulture has been closer to $10 \%$, which represents an inadequate base on which to 
provide a significant number and range of postgraduate-qualified scientists. The import of the argument is that the broadly based four year degree programmes in agricultural, horticultural and forestry sciences have typically provided an excellent background for those involved in working in complex primary production systems. The narrower focus of the biological sciences may limit the effectiveness of inter and multi-disciplinary approaches to plant protection problems. Ideally plant protection requires a balance of backgrounds and experience, in its human resource.

\section{CONCLUSIONS AND THE WAY FORWARD}

It is reasonable to conclude that the significant downturn in the primary production sector as a whole and the desire by the Government to set revised priorities that put increasing emphasis on knowledge and technology-based industries has impacted adversely on plant protection. The shifts have led to a changing capability, but one that may not be declining at the rate supposed. While largely anecdotal it is probably fair to suggest that the broadly-based plant protection generalists are being replaced by specialists who lack the system-wide understanding that previously characterised plant protection. This simply suggests a change of emphasis to meet new scientific requirements, rather than a radical reduction in capability. It has never been possible to match adequately the need for plant protection investigation with the available resources. The challenge is to ensure that New Zealand can meet the increasingly stringent international quarantine and biosecurity requirements to provide for effective international trade in primary production commodities.

\section{REFERENCES}

Anon., 1990. Situation and outlook for New Zealand Agriculture. Ministry of Agriculture and Fisheries.

Anon., 1995. Public investment in strategic science and technology. A review of directions through to the year 2001. Ministry of Research, Science and Technology.

Anon., 1996a. Situation and outlook for New Zealand Agriculture. Ministry of Agriculture and Fisheries.

Anon., 1996b. Graduate employment in New Zealand 1996. New Zealand ViceChancellors' Committee, Report No. 23.

Bourdôt, G.W. and Hurrell, G.A., 1987. Chilean needle grass (Stipa neesiana) I. Control with herbicides in pasture.Proc. 40th N.Z. Weed and Pest Control Conf:: 204-207.

Cameron, K.C., 1996. Policy paper on careers in primay production science and technology. Draft prepared for Royal Society of New Zealand, Committee on Primary Production Sciences and Technologies.

Lewis, T., 1994. Commitment to long-term agricultural research: a message for science, sponsors and industry. Brighton Crop Prot. Conf. - Pests and Diseases: 3-20.

Sinclair, G., Walker, B. and Frampton R., 1997. Pest incursion management : a review of the white spotted tussock moth eradication programme, with recommendations for future biosecurity practice. Report to Minister of Research, Science and Technology.

Williamson, M., 1997. My vision in a nutshell. Sci-tech. 8(1) : 1-3. 